\title{
Development of an E-learning Module and Evaluation of this Method of Teaching to Supplement Traditional Education in Pathology
}

\author{
Rathod, G. ${ }^{1}$ \& Parmar, $P{ }^{2}$
}

\begin{abstract}
Background: E-learning has been introduced as a tool in thE-learning process in the majority of the international universities worldwide. Present study was done to develop and evaluate E-learning module to supplement traditional education in Pathology.

Methods: A standardized E-learning module in Pathology was developed and validated on one 'must know' topic (Peripheral blood smear examination). All 2nd M.B.B.S. students (5th Semester) were subjected to a pre-test questionnaire, the E-learning module and a post-test questionnaire followed by feedback after obtaining their informed written consent. Feedback and suggestions given by the students were analysed.
\end{abstract}

Results: Out of 145 participants, 98 were male and 47 were female. There was no statistically significant difference between perceptions of male and female participants. Comparison of pre and post test scores of students was done using Wilcoxon's sign rank test. Students scored significantly more in post-test. Only 3\% scored less in post-test and $5 \%$ had similar pre- and post-test scores. Frequency and median score of various parameters of feedback given by students showed positive perceptions.

Conclusion: The students' feedback showed that the E-learning method was a very effective way of teaching. In future E-learning should be implemented more frequently in Medical Education, which will create new and exciting opportunities for both educational institutions and students.

Key words: E-learning, Pathology, Evaluation, Traditional education

\section{Introduction}

A learning activity can be defined as an interaction between a learner and an environment, leading to a planned outcome. There are many types of learning methods and theories but E-learning is developing very fast. E-learning as teaching method has been introduced as a tool in thE-learning process in the majority of the international universities worldwide.

${ }^{1}$ Associate Professor, Department of Pathology, GMERS Medical College, Sola, Ahmedabad, Gujarat, India

${ }^{2}$ Professor and Head, Department of Forensic Medicine, GMERS Medical College, Vadnagar, Gujarat, India

Corresponding Author: Professor Pragnesh Parmar Department of Forensic Medicine, GMERS Medical College, Vadnagar, Gujarat, India

Email:drprag@gmail.com
It is extremely important for medical students and physicians to have the appropriate level of skills and knowledge to practice medicine as they are responsible for human lives. Using Elearning to train medical students and physicians is a faster and cheaper method to provide instruction. E-learning could also be used to help improve learners' retention by employing various types of content. It is said to improve retention by incorporating many elements such as quizzes, audios, videos, and interactions among others to reinforce the message to the learners. E-learning provides immediate feedback, and encourages interaction with other e-learners and einstructors by using features such as chat room, discussion boards, and email among others (Cantoni et al., 2004). Both educators and learners can benefit from the development of a good E-learning course. Although the term E-

DOI: http://doi.org/10.4038/seajme.v14i1.237

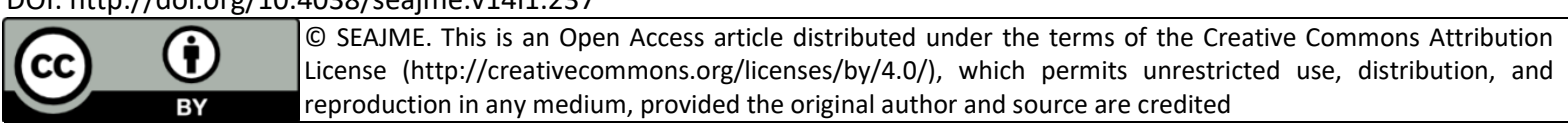


learning and tools have existed for over a decade, use is often limited. So the aim and objectives of the present study were;

- To develop an E-learning module and evaluation of this method of teaching to supplement the traditional education in Pathology.

- To study students' perceptions regarding E-learning as a method of teaching.

\section{Methods}

The present study was conducted at GMERS Medical College, Valsad, Gujarat and the study population was 2 nd M.B.B.S. students (5th Semester). Approval of the Institutional Ethical Committee was taken. A standardized Elearning module in Pathology was developed with the help of departmental faculties, other college faculties, subject experts and the Medical Education Unit team on one "must know" topic (peripheral blood smear examination) of Pathology. The E-learning module and questionnaire were validated by subject experts and later piloting with small sample of students to prior to the actual session. All 2nd M.B.B.S. students (5th
Semester) were subjected to a pre-test questionnaire, the E-learning module and posttest questionnaire followed by feedback after obtaining their informed written consent for Elearning as a method of teaching. Feedback and suggestions given by the students were assessed and analysed.

\section{Results}

A total of 145 students of 2nd MBBS (5th Semester) were subjected to the pre-test questionnaire, E-learning module on peripheral blood smear examination, post-test questionnaire and feedback after obtaining their informed written consent. Frequency and median score of various parameters of feedback given by students were calculated as per Table 1. Out of 145 participants, 98 were male and 47 were female. There was no statistically significant difference between perceptions of male and female participants. Comparison of pre- and post-test scores of students was done using Wilcoxon's sign rank test. Students scored significantly more in the post-test. Only $3 \%$ scored less in post-test and $5 \%$ had similar pre- and post-test scores.

Table 1: Frequency and median score of feedback given by students

\begin{tabular}{|c|c|c|c|c|c|c|}
\hline \multirow[b]{2}{*}{ Question } & \multicolumn{5}{|c|}{ Frequency of responses } & \multirow[b]{2}{*}{ Median } \\
\hline & SD & D & NS & A & SA & \\
\hline $\begin{array}{l}\text { Current method of E-learning via module of Peripheral blood } \\
\text { smear examination is relevant }\end{array}$ & 9 & 13 & 15 & 79 & 29 & 4 \\
\hline $\begin{array}{l}\text { Content of E-learning via Peripheral blood smear } \\
\text { examination module is adequate }\end{array}$ & 10 & 7 & 24 & 83 & 21 & 4 \\
\hline Presentation of E-learning module is adequate & 5 & 6 & 12 & 92 & 30 & 4 \\
\hline $\begin{array}{l}\text { E-learning of Peripheral blood smear examination module is } \\
\text { useful }\end{array}$ & 2 & 5 & 9 & 30 & 99 & 5 \\
\hline Time duration for E-learning is adequate & 5 & 4 & 25 & 83 & 28 & 4 \\
\hline E-learning should be included as a part of syllabus & 12 & 18 & 33 & 60 & 22 & 4 \\
\hline Other topics of Pathology should be taught by E-learning & 14 & 21 & 35 & 55 & 20 & 4 \\
\hline $\begin{array}{l}\text { Such practice of E-learning will improve students' overall } \\
\text { performance }\end{array}$ & 9 & 8 & 9 & 33 & 86 & 5 \\
\hline $\begin{array}{l}\text { Practice of E-learning in other subjects will be helpful for } \\
\text { students }\end{array}$ & 3 & 20 & 35 & 80 & 7 & 4 \\
\hline E-learning is good tool for revision & 3 & 10 & 65 & 42 & 25 & 3 \\
\hline
\end{tabular}




\section{Discussion}

The present medical curriculum has reached its capacity and it is not viable to remove some of the present content to make room for the new information. Additionally, increasing students required hours of instruction is not practically feasible (Ozuah, 2002). Along with this challenge, the field of Medical Education is also facing loss of clinical revenues. Therefore, in such situations providing information in a traditional setting is not plausible. By keeping the busy schedules of the physicians and medical students in mind, medical educators and trainers may opt to use non-traditional options to provide instruction that they can access at their convenience.

E-learning has grown in significance as an educational tool just like technology has developed and progressed over the years. Interestingly, there have been more efforts at advancing technology than on attempting to understand the needs and learning styles of individual learners and instructional design. The 21st century has seen rapid progress with such things as the Internet and onlinE-learning. E-learning is defined as "learning conducted via electronic media, typically on the Internet".

In the present study, the effectiveness of Elearning is discussed. The effectiveness of $\mathrm{E}$ learning is marked by its ability to achieve statistically significant effect on improving learners' knowledge. According to our study, the post-test scoring was high as compared to the pre-test scoring which showed the effectiveness of the E-learning module. Many researchers found that there was statistically significant improvement in learners' knowledge. The use of asynchronous E-learning modules led to an increase in learners' post-test scores (Boye et al., 2012; Gaikwad \& Tankhiwale, 2014).

In the present study the E-learning module was used as to supplement the traditional teaching because the basic knowledge of peripheral blood smear examination was already introduced to the students in the first year study. The same study was done by Boye $\mathrm{S}$, et al. (Boye et al., 2012). The E-learning module in this study provided coaching on immunology. It was found that students who used the Elearning modules had higher scores on the immunology test than students who did not use the E-learning module. Additionally, the researcher found that intermediately skilled students benefitted from the E-learning modules more than the less skilled or best skilled students. The results indicate that Elearning could be used as a supplement method of teaching to the traditional teaching and hence to improve learning (Boye et al., 2012).

Along with assessing the effectiveness of $\mathrm{E}$ learning instructions, is important to consider how learners perceive the E-learning instructions. Specifically, it is imperative to assess students' perceived satisfaction with and usability of E-learning. In our study, the students' feedback showed that they feel it is the best tool for study and revision too. They want such E-learning module for every important topic of Pathology as well as for other subjects too. After reviewing the articles, it is found that overall students perceived Elearning modules as easy to use, had no technical difficulties and found that the students accepted the E-learning activity and perceived it as "innovative, convenient, flexible, and useful" (Gaikwad \& Tankhiwale, 2014; Truncali et al., 2011). It was found that the students largely had good impression about the Elearning program. Khasawneh, et al. reported that approximately $70 \%$ of the students who completed the E-learning module on infection control and $72 \%$ of the students who completed the E-learning module on congenital infection reported some satisfaction or good satisfaction for using E-learning modules as learning tool (Khasawneh et al., 2016).

\section{Conclusion}

The present study concluded that in today's era of technology E-learning is very useful to medical students. E-learning is being used as educational intervention in medical education. The students' feedback showed that its very effective way of teaching. In future E-learning should be implemented more frequently in Medical Education, which will create new and exciting opportunities for both educational institutions and students.

\section{Acknowledgements}

Authors are thankful to faculties of GSMCFAIMER, Mumbai for their guidance and support. This article is a part of educational project done by Dr. Gunvanti Rathod as GSMCFAIMER fellowship.

\section{References}

Cantoni, V., Cellario, M. \& Porta, M. (2004) Perspectives and Challenges in E-learning: Towards Natural Interaction Paradigms. Journal 
of Visual Languages \& Computing, 15, 5, pp.333345.

Ozuah, P.O. (2002) Undergraduate Medical Education: Thoughts on Future Challenges. BMC Medical Education, 2, 1, pp.8.

Boye, S., Moen, T. \& Vik, T. (2012) An E-learning Course in Medical Immunology: Does it ImproveLearning Outcome?. Medical teacher, 34, 9, pp.e649-e653.

Gaikwad, N. \& Tankhiwale, S. (2014) Interactive ELearning Module in Pharmacology: a Pilot Project at a Rural Medical College in India. Perspectives on Medical Education, 3, 1, pp.15-30.
Truncali, A., Lee, J.D., Ark, T.K., Gillespie, C., Triola, M., Hanley, K., Gourevitch, M.N. \& Kalet, A.L. (2011) Teaching Physicians to Address Unhealthy Alcohol Use: A Randomized Controlled Trial Assessing the Effect of a WebBased Module on Medical Student Performance. Journal of Substance Abuse Treatment, 40, 2, pp.203-213.

Khasawneh, R., Simonsen, K., Snowden, J., Higgins, J. \& Beck, G. (2016) The Effectiveness of E-learning in Pediatric Medical Student Education. Medical Education Online, 21, 1, pp.29516. 